\title{
A phenomenology of the other world
}

Shannon Hayes

Dorothée Legrand and Dylan Trigg, eds, Unconsciousness between phenomenology and psychoanalysis, Springer, 2017

Unconsciousness between phenomenology and psychoanalysis developed out of the 2014 conference titled "Is there a phenomenology of unconsciousness?" As Dorothée Legrand and Dylan Trigg make clear in the introduction, this volume is not intended to be a dialogue between phenomenology and psychoanalysis, nor is it meant to be an index of their interactions, nor to compare their approaches. By and large, the authors in this volume are approaching the unconscious phenomenologically - that is, approaching it with a methodology closely associated with a philosophy of consciousness. While phenomenology calls for first-person, descriptive accounts of lived experience, the unconscious has long been characterized as that which withholds itself from consciousness and is, if not inaccessible to conscious, then distinct, a resistance to consciousness within consciousness itself. How, then, to make the unconscious appear when it is defined by its non-appearance? By virtue of this approach, the authors take on a difficult task, which is not, strictly speaking, to make the unconscious appear, but to dwell with the tensions and aporias that inevitably emerge from such an endeavor.

A recurrent figure across this volume is Maurice Merleau-Ponty. That the thinking of Merleau-Ponty would reverberate across these pages is not surprising given the progression of his own thought, from a phenomenology of perceptual consciousness (1945) to a growing interest in the unconscious and a growing desire to "elaborate a phenomenology of "the other world"' (1960)..$^{1}$ Merleau-Ponty's interest was meant to indicate neither an assimilation of phenomenology to psychoanalysis nor a radical break with the psychoanalytic tradition. The essays in this volume attest to this and, on my reading, offer the material for another

\footnotetext{
${ }^{1}$ Maurice Merleau-Ponty. The Visible and the Invisible, trans. Alphonso Lingis (Evanston, Il: Northwestern University Press, 1968), 229.
} 
"return to Freud." This time it is Merleau-Ponty's non-Lacanian return to Sigmund Freud - a non-structuralist, silent (James Phillips) or, at least, not-entirely-verbal (Thamy Ayouch) path for the bodily unconscious to traverse; one that is not anonymous but rather like the glue that binds the personal and interpersonal (Emmanuel Saint Aubert, Legrande). Like the Lacanian return to Freud, this would not be a return to the positive project of Freud. As Merleau-Ponty explains in a 1960 Preface, upon re-reading Freud, he was struck by what he encountered in his "return": "his polymorphous perception of work, of acts, of dreams...this prodigious intuition of exchanges-exchange of roles, exchange of the soul and the body, of the imaginary and the real...this universal promiscuity." ${ }^{2}$ These were the same movements of being that defined a philosophy of flesh, and that he would spend the last years of his life trying to bring to expression. Despite the divergences of psychoanalysis and phenomenology, according to Merleau-Ponty, they shared a directionality and were oriented "toward the same latency."

While discussing the public exchanges between Jacques Lacan and Merleau-Ponty, Phillips offers a helpful reminder that could be addressed to readers of the volume as a whole: "It is important to keep in mind the different contexts: on the one hand, the clinician is dealing with the unconscious in the context of symptoms and treatments; on the other, the philosopher is recognizing that the unconscious brings an unknown depth to phenomenology and is trying to grasp it philosophically" (90). As a philosophical object, the unconscious in this volume is necessarily wrested from the therapeutic, psychoanalytic contexts that give it the weight of its significance and approached conceptually. "If unconsciousness is a concept," the editors write, "then it must be robust enough to be extracted from its native field, to support exportation, if not deterritorialization, to be modified by its contact with other concepts it didn't touch initially, without losing its defining core" (ix).

\footnotetext{
${ }^{2}$ Maurice Merleau-Ponty. "Phenomenology and Psychoanalysis: Preface to Hesnard's L'Oeuvre de Freud." Review of Existential Psychology and Psychiatry, Vol.18, No.1-3 (1982-83): 68.

3 Ibid., 71. (italics in original)
} 
Like the failures of the phenomenological reduction, one finds in these essays a similar "failure" of phenomenology to fully conceptualize the unconscious. What emerges from these failures is what emerges from every expression - something truly new. What phenomenology brings to the study of the unconscious is the generative multiplicity of the unconscious and what the unconscious brings to phenomenology is a greater attention to the limitations of the tradition - limits that mark the edges across which thought has yet to traverse. By attending to the loci of resistance within the phenomenological project, this volume breathes new life into the tradition and will be a great resource for anyone interested in the future of phenomenology.

In Part I, Dermot Moran and Alexander Schnell approach the unconscious from within the Husserlian phenomenology of consciousness. By remaining tied to Husserlian phenomenology, both essays demonstrate that the unconscious, instead of serving as a point of resistance against the efficacy of the phenomenological project, is key to any analysis of human consciousness. Although Edmund Husserl and Freud were contemporaries, a dialogue between the two never took place. What emerges in these essays is the outline of an unconscious relatively untouched by the Freudian psychoanalytic tradition.

It is toward the construction of a fruitful dialogue between Husserl and Freud that Moran's essay is directed. On first glance, striking differences characterize the projects and interests of each. While Husserl's phenomenology is characterized by its concern with the rational, conscious subject, Freud's psychoanalysis tends to be characterized as a depth psychology. After Husserl, phenomenology was conceived and reconceived by figures like Merleau-Ponty, Martin Heidegger, and Jean-Paul Sartre, who deepened phenomenology and made it approach the field and concerns of psychoanalysis. Not merely satisfied with the way that Husserl's successors transformed his phenomenology, Moran returns to the "mature Husserl" and draws out those elements of his account of human subjectivity that call 
attention to the complex textured unity of the person and echo key ideas in Freudian psychoanalysis.

Like Moran, Schnell problematizes the characterization of phenomenology as a philosophy of consciousness by showing the ways in which the unconscious is central to any generative phenomenology that claims to produce more than a merely descriptive account of phenomena, and attends, rather, to the genesis of meaning itself. According to Schnell, the "paradox of consciousness" points to a notion of the unconscious as the transcendental conditions of consciousness. Towards developing a positive account of the phenomenological unconscious, Schnell articulates its three fundamental types in the act of imaging (genetic, hypostatic and reflexible), and in the process, uncovers a multi-layered unconscious grounding perception.

In Part II, Timothy Mooney, Emmanuel Saint Aubert, and James Phillips re-read the development of Merleau-Ponty's phenomenological project in conjunction with the development of the thought of the unconscious. Mooney focuses on the unconscious as it is articulated in Phenomenology of Perception, a text in which Merleau-Ponty works to wrest psychoanalytic concepts from Freud's causal, mechanistic structure and deploy them within a phenomenological framework. Mooney explores the congruencies between phenomenology and psychoanalysis and the divergences that center on the role of the body. In Phenomenology of Perception, accounts of abnormal body functioning give way to phenomenological descriptions of normal body functioning. As Mooney shows, the body itself is revealed there where bodily integration fails, like experiences of a phantom limb. If there is a deficiency in Merleau-Ponty's account, Mooney claims it is that he is oriented toward integration, synchronization, general well-being, and "does not quite convey the jagged and fractured character of a genuine human presence in the world, even one that is ordinarily unhappy" (73).

Saint Aubert charts the genesis of Merleau-Ponty's thought of "unconsciousness," and in the process, demonstrates the continuity of his thought from The Primacy of Perception to 
The Visible and the Invisible. Like the phenomenal reduction itself, the resistances to consciousness that unconsciousness presents serve to deepen the phenomenological project to the point of its completion. Saint Aubert follows Merleau-Ponty as unconsciousness, conceived negatively at first, gives way to a positive conception in his lectures on passivity (1955). Unconsciousness is not hidden from consciousness but is excessive - it is the excess of the perceptual over the notional and of oneiric experience over perception (48), everywhere enveloping the real in the texture of the imaginary. In subsequent writings, the unconscious is articulated as desire, the libidinal body characterized by openness and participation in being. As Saint Aubert shows, Merleau-Ponty develops a "non Freudian 'return to Freud', according to a double accentuation of body and being: 'consciousness and unconsciousness defined in terms of body"' (56).

Phillips, too, charts the genesis of Merleau-Ponty's unconscious, but on his analysis, Merleau-Ponty is shown to be elaborating a non-Lacanian "return to Freud," and with it, a non-verbal unconscious that finds its fullest articulation in The Visible and the Invisible. Phillips tracks the formulations of the unconscious beginning with The Structure of Behavior in which the unconscious is encountered in a subject's unintegrated behavior and formulated in terms of the "ambivalence of immediate consciousness" (77). In Phenomenology of Perception, the unconscious is depathologized and coterminous with embodied, perceptual consciousness, which is ambiguous, opaque, and bound to the world; it is the lived, unclear aspects of unreflective life. In the Sorbonne lectures, Merleau-Ponty approaches the unconscious through the Gestalt metaphor of figure/ground that he had introduced in Phenomenology of Perception: the unconscious is the "unnoticed ground" that is not known but lived by us.

As Merleau-Ponty turns toward articulating a nonrepresentational theory of language, he emphasizes the absences and silences of speech and writing as key to expression and meaning. Philips shows Merleau-Ponty in his Collège de France lectures approaching the unconscious through the oneirism at play in dreams and waking relations. 
As "oneiric consciousness," the unconscious is perceptual and symbolic, characterized by the promiscuity, reversibility, and invisibility central to his theory of language. The unconscious is "the silent, unheard, unexpressed structure that makes expression, whether speech or painting or any other form of expression, possible" (88).

In Part III, Dorothée Legrand, Francois Raffoul, Joseph Cohen, and Drew Dalton shift away from the task of developing a phenomenology of the unconscious and instead investigate the unconscious as that which is at the limit of phenomenology. The task is not to make the unconscious appear, but to attend to that which "appears" in not appearing, a concealment at the heart of the phenomenon. What emerges in these essays is an unconscious that is primarily ethical.

Legrand explores the unconscious that emerges at the limit of the phenomenologies of Heidegger, Merleau-Ponty, and Emmanuel Levinas. In each case, Legrand uncovers the relationship between the unconscious and consciousness and she demonstrates that every philosophical account of consciousness is coterminous with an account of the unconscious; the one cannot be articulated without the other. Unconsciousness as the "other" to consciousness is here meant in (at least) two senses. First, the unconscious is the primordial ground, wellspring, or indifferentiation from which consciousness emerges as differentiated I, ego, or subject. Second, the unconscious is shown to be, if not intersubjective, then intercorporeal: it is the hinge, the glue that binds the subject to different dimensions of themselves and to others.

Like Legrand, Raffoul draws on Heidegger and Levinas to make the case that the unconscious is at the limit of phenomenology and that it consists of an ethical relation with the other. This ethical relation is the secret of our being that phenomenology directs itself toward but does not itself rise to the level of appearance; it haunts consciousness. With Heidegger, Raffoul explores what Heidegger means by a "phenomenology of the inapparent." As much as phenomenology is associated with a philosophy of presence, its presence is generated by that which does not make itself present, by what withholds itself. 
With Levinas, he shows that what withholds itself is the face of the other, which does not appear to perception and cannot be thematized by the intellect. The (non)phenomenality of the face consists of the exposure, the vulnerability of the other, and bears the secret of their death. According to Raffoul, this exposure "to the non-appearing of death, takes on an ethical significance: I become responsible for the death of the other" (125). At the limits of phenomenology is an ethical relation and responsibility for the other and it is through phenomenology's investigation into the phenomenon that this relation becomes "apparent."

Cohen's essay further develops the theme of haunting. Cohen situates phenomenology's privileging of presence within the day, the boundaries of which mark the limits of its domain. In contrast, the night is characterized by the indifferentiation of subject and its world and exceeds the limits of phenomenology. The "unconscious," as that which “appears" in the undifferentiated night, cannot appear to consciousness. Despite this, Cohen explores whether it can be "encountered" through the spectrality of the "unconscious" as that which haunts consciousness. The unconscious reveals itself as an "undifferentiated, unconditional, indeterminable play between presence and absence" that disrupts the distance and separation that otherwise characterizes the subject's relation to the world (140).

Dalton explores the limitations of phenomenology and gives flesh to the unconscious that haunts consciousness by situating it in the experience of encountering a dead body. On phenomenology's limitations, he emphasizes the same criticism that Husserl contended with in his writings, namely, that it is always at risk of resolving into either a psychologism or a naturalism. Dalton follows a path charted by Heidegger and more recently by speculative realists who claim that the failures of phenomenology are tied to the correlationist inheritance linked to the adoption of a Cartesian/Kantian notion of subjectivity. While Heidegger attempted to right this by foregoing the modern notion of the subject altogether, Dalton finds in Heidegger's analysis of death a hidden correlationism tied to Dasein's ultimate appropriation of everything excessive and inhuman. The only power that Heidegger 
attributes to the dead body is to remind Dasein of its authentic existence as being-towardsdeath. What Heidegger misses in the appearance of the dead other is "the radical inhuman alterity of the dead body," and with it, the power that Freud and Lacan attributed to the uncanny (151). That the dead body is uncanny means that it is a traumatic phenomenon which interrupts the organization of the subject's perceptual field by bringing to the fore something that had been hidden. With Lacan, the uncanny is the appearance of something that interrupts the symbolic order of representation and, like a black hole, draws one into the raw material of the Real that is the ground of representation, and threatens the subject's organization. The uncanny dead body thus draws the perceiver back toward the inhuman, anonymous things themselves, whose existence exceeds the subject's own experience and remains unintelligible.

Both Cohen and Dalton suggest that we need a new language to speak of the unconscious. Cohen suggests that we need a new language to speak of the spectrality of the unconscious - one that is tied to the language that we use in mourning the other (140). Cohen's suggestion is reminiscent of Jacques Derrida's discussions of language and the impossible faithfulness to the other that mourning demands. Dalton claims that we need a new language to speak of the inhuman as revealed in the uncanniness of the corpse. This is the task of speculative realists like Graham Harmon who are working toward an objectoriented ontology and one that Dalton finds already at play in Levinas' analyses of $i l y a$ as the anonymous ground of being in general.

The essays featured in Part IV (Dylan Trigg, Thamy Ayouch, Dieter Lohmar and Lyne Ryberg Ingerslev) each develop an account of the unconscious while emphasizing the depersonalization, anonymity and self-withdrawal that is constitutive of subjectivity. In the process, these essays take up the Merleau-Pontian task of depathologizing psychophysical states and call attention to the limitations of traditional notions of subjectivity.

In his essay, Trigg analyzes the phenomena of hypnagogia (liminal states between sleep and wakefulness) and anxiety, and claims that such states give one access to the 
primordial, oneiric ground of selfhood that characterizes Merleau-Ponty's bodily unconscious. Both hypnagogia and anxiety feature an encounter with an impersonal, anonymous body that no longer flows according to personal time (hence their fragmented narratives), but "flows" along an anonymous, general time that does not belong to the subject. In hypnagogia, this encounter is experienced as pleasurable: the subject experiences the disentanglement of consciousness from the ego, explores the porous boundaries of selfhood and feels privy to a special kind of insight. In anxiety, the "insight" it intimates and the porous boundaries of selfhood are experienced as a threat of annihilation to the self. To the anxious subject, normal ambiguity threatens to disorder the self. Trigg's point is that these experiences share a structural and temporal affinity and, aligned with Merleau-Ponty's concern with depathologizing psychophysical states, and are shown to be non-pathological, impersonal modes of selfhood. Both states give the subject access to the unconscious as the "oneiric ground upon which states of consciousness form and deform" (177). This oneirism is not derivative or secondary but is the ground of waking, perceptual life.

Ayouch, too, is interested in the oneiric, bodily unconscious developed by MerleauPonty in his later lectures and texts. With this notion of the unconscious, Ayouch aims to demonstrate the possibilities in Merleau-Ponty's phenomenology, which is characterized as a phenomenology of affectivity, for a queer phenomenology that can account for the multiplicity of non-binary genders and sexualities. By grounding the unconscious on the body, affect, and intersubjective relations, Ayouch shows Merleau-Ponty to be developing a notion of the unconscious that, unlike Lacan, is not primarily linguistic. This means that Merleau-Ponty's unconscious is not structured by the problematic, universalizing stories (Oedipus complex, castrations, etc.) that are used to render unintelligible and pathologize non-binary genders and sexualities.

Lohmar returns to the paradox of consciousness, which states that we can know and not know something at the same time, in order to articulate a non-Freudian notion of the unconscious. While Freud responded to the paradox by introducing the unconscious as a 
separate domain, inaccessible to consciousness, Lohmar claims that this enigma can be understood by articulating the differences between the nonlinguistic and linguistic systems of thinking. Nonlinguistic modes of thinking, like daydreaming, involve the replay and repetition of scenes which modify the past scenes for the purpose of uncovering something useful for future actions. Especially when the modified scene is one of a traumatic experience, the modifications of the scene may result in new behaviors that seem disconnected from the original traumatic scene (as a way of protecting the subject). Lohmar concludes that the activity of nonlinguistic thinking can result in neurotic displacements where the subject both knows and does not know something at the same time.

Ingerslev challenges the traditional Western notion of agency as tied to a self that is fully conscious, rational, and reflective. In fact, our engagements with ourselves and the world tend to mostly take place within the realm of habit - as unreflective, involuntary, or automatic actions. For Ingerslev, this evinces an alienness - a self-withdrawal, temporal delay, anonymity - at the heart of selfhood, one that "prevents us from experiencing ourselves as fully unified autonomous agents and thus as the primary rational source of our own actions" (225). A more inclusive notion of responsive agency should take into account these experiences of self-withdrawal as constitutive of the self. With habits, there is one in me who acts in my name and even though I am not fully aware of having acted, I take responsibility for the action. Agential freedom, according to Ingerslev, has to do with surrendering to our habits. Habits are answers to questions long forgotten. By surrendering to habits we give ourselves over to their incomprehensibility and offer another response; by responding to our habits we re-appropriate them along with the past and the past selves that have yet to be integrated. In other words, we become who we are by surrendering to the otherness within.

In Part V, Natalie Depraz and Alphonso Lingis draw from phenomenology a lived, experiential account of the unconscious while moving decidedly beyond phenomenology. Depraz develops the notion of "heart-unconscious," offering an account of the unconscious 
that is physiological and centered on the heart-organ instead of brain processes. By not relying on the brain, Depraz is able to account for the lived experience of the unconscious as well as its affective-emotional features. As she notes, the heart beating is something that occurs without conscious awareness, but something a subject can turn to and become conscious of, and so an account of the lived experience of heart-unconscious is possible because of the subject's direct perceptions of the heart (242). Depraz is interested in surprise as a multivectorial process that serves as an intriguing marker of heart unconscious. Through a physical experiment she administers to student participants, she analyzes the cognitive, emotional and bodily responses involved in surprise and the way these responses are affected by depression.

Lingis departs from the Freudian psychoanalytic unconscious and follows instead the unconscious as investigated by the Surrealists. Surrealists, like André Breton, had no interest in putting the unconscious to work in therapeutic contexts and making it be at the service of consciousness. The Surrealists were interested in liberating the unconscious to better integrate the "world that the unconscious addresses and reveals with that perceived by the conscious mind" (271). The unconscious processes bear an inexhaustible creative reservoir of new connections, objects, and events. The goal is not to put the unconscious to work in the production of works of art, but to follow it for its own sake - for the beauty, the pleasure, the virtue that it reveals about the world and oneself. Lingis' essay serves to help the reader question the motivations for phenomenology's interest in the unconscious and delimit phenomenological objectives from psychoanalytic ones. Phenomenological descriptions of the unconscious need not travel the way of psychoanalysis and make the unconscious serve waking, conscious life. Bringing the unconscious to expression can instead add to the beauty and richness of life itself.

@2021 Shannon Hayes 


\section{References}

Legrand, Dorothée and Dylan Trigg (Editors). Unconsciousness between Phenomenology and Psychoanalysis. New York: Springer, 2017.

Merleau-Ponty, Maurice. "Phenomenology and Psychoanalysis: Preface to Hesnard's L'Oeuvre de Freud." Review of Existential Psychology and Psychiatry, Vol.18, No.1-3 (1982-83): $\quad$ 67-72.

---. The Visible and the Invisible, translated by Alphonso Lingis. Evanston, II: Northwestern University Press, 1968. 